Article

\title{
A Parcel-Level Model for Ranking and Allocating Urban Land-Uses
}

\author{
Jamshid Maleki $^{1}$ (D), Farshad Hakimpour ${ }^{1, *}$ and Zohreh Masoumi ${ }^{2}$ \\ 1 School of Surveying and Geospatial Engineering, College of Engineering, University of Tehran, \\ Tehran 1439957131, Iran; j.maleki@ut.ac.ir \\ 2 Faculty of Earth Sciences, Institute for Advanced Studies in Basic Sciences (IASBS), Zanjan 4513766731, Iran; \\ z.masoumi@iasbs.ac.ir \\ * Correspondence: fhakimpour@ut.ac.ir; Tel.: +98-21-611-14520
}

Received: 14 June 2017; Accepted: 21 August 2017; Published: 31 August 2017

\begin{abstract}
Urban land-use allocation is a complicated problem due to the variety of land-uses, a large number of parcels, and different stakeholders with diverse and conflicting interests. Various approaches and techniques have been proposed for the optimization of urban land-use allocation. The outputs of these approaches are almost optimum plans that suggest a unique, appropriate land-use for every land unit. However, because of some restrictions, such stakeholder opposition to a specific land-use or the high cost of land-use change, it is not possible for planners to propose a desirable land-use for each parcel. As a result, planners have to identify other priorities of the land-uses. Thus, ranking land-uses for parcels along with optimal land-use allocation could be advantageous in urban land-use planning. In this paper, a parcel-level model is presented for ranking and allocating urban land-uses. The proposed model benefits from the capabilities of geographic information systems (GIS), fuzzy calculations, and Multi-Criteria Decision-Making (MCDM) methods (fuzzy TOPSIS), intends to improve the capabilities of existing urban land-use planning support systems. In this model, as a first step, using fuzzy calculations and spatial analysis capabilities of GIS, quantitative and qualitative evaluation criteria are estimated based on physical characteristics of the parcels and their neighborhoods. In the second step, through the fuzzy TOPSIS method, urban land-uses are ranked for each of the urban land units. In the third step, using the proposed land-use allocation process and genetic algorithm, the efficiency of the model is evaluated in urban land-use optimal allocation. The proposed model is tested on spatial data of region 7 , district 1 of Tehran. The implementation results demonstrate that, in the study area, the land-use of $77.2 \%$ of the parcels have first priority. As such, the land-use of $22.8 \%$ of the parcels do not have first priority, and are prone to change.
\end{abstract}

Keywords: urban land-use planning; planning support systems; fuzzy calculations; fuzzy TOPSIS

\section{Introduction}

Urban land-use planning (ULUP), as the main core of urban planning, allocates various land-use types to the different land units and causes the urban activities to become more organized based on the requirements of urban society [1]. The process of allocating various urban land-uses to the numerous urban land units by considering various and conflicting objectives is a complicated spatial decision problem [2,3]. Most spatial decision-making problems lie somewhere between two extremes, completely structured and unstructured problems, so-called semi- or ill-structured problems [4]. ULUP, as a spatial decision-making problem, can also be considered as a semi-structured problem in that its structured aspects may be amenable to models and automatically generated solutions, and its unstructured aspects are tackled by the contribution of urban planners as decision-makers [4]. Computer-based systems like Planning Support Systems (PSS) and Spatial Decision Support Systems (SDSS) have been developed to solve semi-structured spatial problems $[4,5]$. PSSs are a set of tools related to geo-information 
technology that collectively supports the whole, or a part, of a specific planning task by incorporating a suite of components, such as theories, data, knowledge, and methods, etc. [5]. SDSS are also interactive computer-based systems that have been designed to support a group of individuals to achieve higher effectiveness in solving some spatial decision-making problems [6].

Generally, SDSS can be considered as a technical framework for PSS and can be served as an assistant tool for ULUP-related decision-making [7]. In order to support spatial decision-making by SDSS, two different approaches have emerged at the operational level [8]. The first approach is dealing with multi-criteria evaluation (MCE), and the second one involves applying spatial optimization methods to support spatial decision-making. In the former approach, an overall suitability map for a land-use, or a special facility, is estimated by combining MCE and spatial analysis operations. This overall suitability can be utilized to determine suitable locations. In many studies, the first approach (i.e., GIS-based MCE) have been applied for site selection of facilities, such as hospitals [9], renewable-energy systems [10], parking [11], landfill [12], and different land-uses, such as residential, commercial, industrial, and so on [13-15]. For example, in [14] an evaluation of land suitability has been done for urban land-use planning. In this study, urban residential land-use has been emphasized and the suitability for ULUP has been determined using a GIS-based analytical hierarchy process method. Using the GIS-based MCE approach is feasible only for determining the suitability of just one land-use or only a kind of facility [14].

The second approach (i.e., spatial optimization methods) is applied when several land-use types or different facilities are considered simultaneously with different objectives and constraints. Allocation of various land-use types to several land units in order to reach an optimal land-use layout based on multiple objectives and constraints can be considered as a multi-objective optimization problem. The classic optimization techniques, such as linear programming $[16,17]$ and heuristic or metaheuristic algorithms, are used by researchers to solve these optimization problems. Heuristic and metaheuristic algorithms can be used to solve the ULUP in two approaches: weighting prior to solving the problem [2,18] and using the concept of the Pareto front [19-22]. For instance, in [23] goal programming as one of the weighting approaches is used for modeling the problem, and the Genetic Algorithm (GA) is applied to solve it. One of the Pareto-based algorithms is NSGA-II [22], which is applied to obtain the non-dominated solutions of ULUP. By increasing the number of objectives in ULUP, many non-dominated solutions and their inappropriate diversity in the Pareto front are disadvantages of the Pareto-based multi-objective optimization algorithms [24]. Additionally, other spatial modeling, such as cellular automata [25] and agent-based [26,27] models, have been used in the ULUP to obtain optimal land-use layouts.

According to the above-mentioned studies, many attempts have been made to present effective models for ULUP to achieve the optimal land-use plans. Although among these models, there are some models to rank different sites according to their suitability for a specific land-use or facility [13,28,29], but to the best of our knowledge, there is not much work on the urban land-use allocation model with the ability to rank all urban land-use types for each parcel. Ranking and allocating urban land-uses in the form of an urban land-use planning support system provides the urban planners a suite of ranked land-use alternatives that, if needed, they can select another appropriate alternative land-use for each parcel. Therefore, in this paper, we propose a parcel-level model for ranking and allocating urban land-uses. This model calculates neighborhood effects using fuzzy calculations, due to better adoption with qualitative values assigned to land-use interactions. Then, it ranks the land-use types for each parcel with respect to neighborhood effects, land suitability, and per capita demand, using the fuzzy TOPSIS method. Given that urban land unit boundaries are irregular polygons and not regular cells, the vector data is used that is more compatible with parcel boundaries in an urban area. Additionally, urban land-uses have different effects on each other, based on different service levels (local, district, and regional) [25]. Thus, in the proposed model, different effects of the land-uses have been taken into account in determining the evaluation criteria of parcels, with considering three different service levels and different radii of effects. Finally, various land-use layouts can be derived by defining a process based on land-use rankings 
for each parcel. According to the above description, the characteristics of the proposed model can be mentioned in the following:

- Using the vector data for modeling urban parcels that are more compatible with the boundaries of the urban area.

- Using fuzzy calculations to calculate the neighborhood effects of the land-uses.

- Considering three different service levels with a different radius of effect for each land-use.

- Ranking land-uses for each urban parcel.

- $\quad$ Suggesting alternative land-use maps based upon rankings of land-uses for each parcel.

The rest of the paper is organized as follows: In the next section, some of the concepts and techniques used in this research are briefly stated. The proposed model and its constituents are illustrated in Section 3. The real case study and implementation details are clarified in Section 4. The results and discussion of implementation are illustrated in Section 5. Finally, in Section 6, the conclusions are presented.

\section{Preliminaries}

In this section, some basic concepts being essential in a better explanation of the proposed model are described.

\subsection{Fuzzy Numbers and Arithmetic Operations}

Fuzzy numbers are fuzzy sets defined on the real numbers that are applied to represent approximate expressions [30]. Depending on the type of functions that are employed to estimate the amount of membership, different types of fuzzy numbers can be defined. Among well-known fuzzy numbers, triangular, trapezoidal and Gaussian can be mentioned [31]. In this study, because of the ease and speed of calculation, the triangular fuzzy numbers is used. Due to using fuzzy operators in this study, some of these operators is introduced in this section. It should be noted that algebraic operations on real numbers can be extended using the extension principle to apply fuzzy numbers [32]. Assuming (a) and (c) denote the left-hand and right-hand of a fuzzy number respectively, and (b) the modal value, some algebraic operations on fuzzy numbers A1 and A2 can be defined as per Equations (1)-(7) [33].

$$
\begin{gathered}
A_{1} \oplus A_{2}=\left(a_{1}+a_{2}, b_{1}+b_{2}, c_{1}+c_{2}\right) \\
A_{1} \ominus A_{2}=\left(a_{1}-a_{2}, b_{1}-b_{2}, c_{1}-c_{2}\right) \\
A_{1} \otimes A_{2} \approx\left(a_{1} \times a_{2}, b_{1} \times b_{2}, c_{1} \times c_{2}\right) \\
A_{1} \oslash A_{2} \approx\left(a_{1} / c_{2}, b_{1} / b_{2}, c_{1} / a_{2}\right) \\
k \otimes A_{1}=\left(k \times a_{1}, k \times b_{1}, k \times c_{1}\right), k \in R, \\
k \oslash A_{1}=\left(k / c_{1}, k / b_{1}, k / a_{1}\right), k \in R \\
\ln \left(A_{1}\right) \approx\left(\ln \left(a_{1}\right), \ln \left(b_{1}\right), \ln \left(c_{1}\right)\right), k \in R,
\end{gathered}
$$

In which, $\oplus, \ominus, \otimes$, and $\oslash$ denote, respectively, fuzzy addition, subtraction, multiplication, and division operators.

To calculate the distance between two triangular fuzzy numbers the following equation can be used [34]:

$$
d\left(\widetilde{a}_{1}, \widetilde{a}_{2}\right)=\sqrt{\frac{1}{3}\left[\left(a_{1}-a_{2}\right)^{2}+\left(b_{1}-b_{2}\right)^{2}+\left(c_{1}-c_{2}\right)^{2}\right]}
$$

Defuzzification of a triangular fuzzy number $\widetilde{A}(a, b, c)$ can be accomplished as follows [35]:

$$
D=\frac{1}{2} \int_{0}^{1}[\underline{u}(x)+\bar{u}(x)] d x=\frac{1}{4}(a+2 b+c),
$$


where $\underline{u}(x)$ and $\bar{u}(x)$ are the left and right membership functions of $\widetilde{A}$.

\subsection{Linguistic Variables}

Linguistic variables are those whose values can be expressed by word or sentence [36]. For example, compatibility between two land-uses is a linguistic variable if its values are linguistic, i.e., highly incompatible (HI), moderately incompatible (MI), low/neutrally compatible (NC), moderately compatible (MC), and highly compatible (HC). In order to use linguistic variables in fuzzy calculations, linguistic values are expressed in the form of fuzzy numbers. In Figure 1, membership functions of linguistic values for determining compatibility between land-uses are demonstrated.

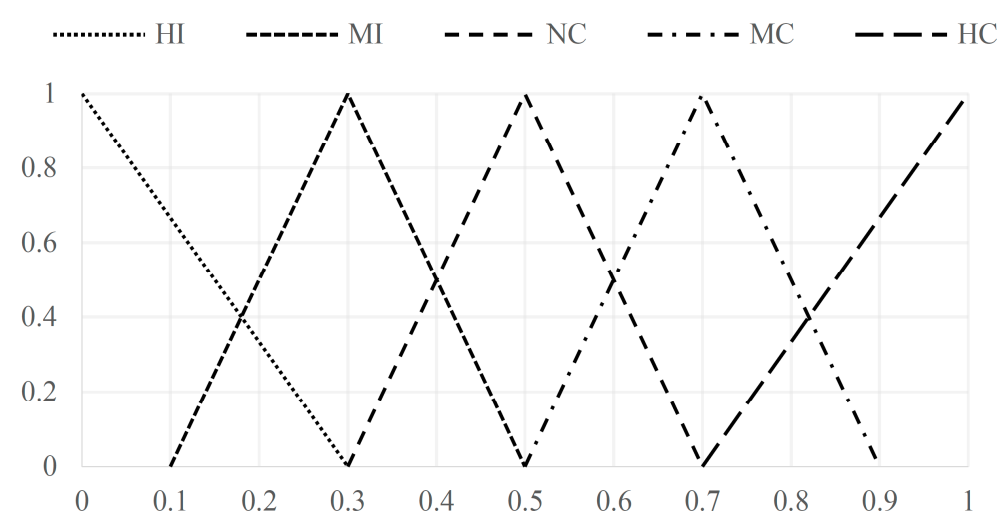

Figure 1. Membership functions of linguistic values for determining compatibility between land-uses.

\section{Methodology}

In this section, we explain the proposed model for ranking the land-uses for each urban parcel. In the proposed model, decision-making criteria are calculated for all land-uses for each parcel; then the land-uses are ranked for each parcel by fuzzy TOPSIS [34]. The model criteria include the effects of neighboring parcels, suitability, and per capita demand, which have been mentioned in many studies $[3,21,22,25]$. It should be noted that except for the criteria mentioned above, there are many other criteria for urban land-use planning, such as equity and socio-economic criteria [37-39]. Due to simplicity, in the proposed model, only the most widely-used criteria are met. To obtain the effects of neighboring parcels, first, the neighborhood of parcels is defined and then neighborhood effects are determined by fuzzy calculations. The effects of neighborhood criteria consist of compatibility, dependency, and compactness. In this model, the suitability of each parcel is estimated and participates in the decision-making process in a fuzzy manner. Per capita demand participates in the model as a violation function. All criteria for land-use ranking are obtained based on current status of the land-uses in the study area. In the proposed model, the area of parcels does not play a role in the calculation of the criteria, and the effects of the area in the land-use arrangement are controlled only by the per capita criterion. After criteria calculation, the relative importance of each criterion to other criteria is obtained based on expert knowledge. Finally, ranks of land-uses for each parcel are obtained through fuzzy TOPSIS. The overall steps of the proposed model is shown in Figure 2. 


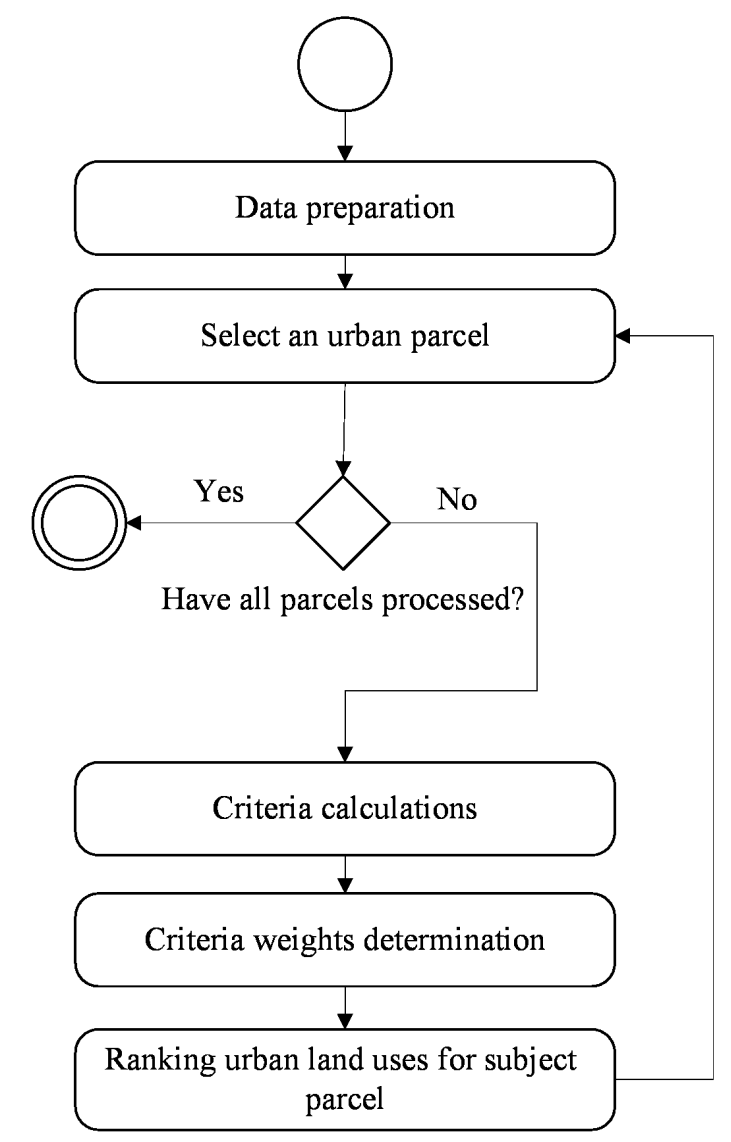

Figure 2. The overall steps of the proposed model.

\subsection{Calculating Decision-Making Criteria for Urban Parcels}

This section defines the neighborhood of parcels and then describes the fuzzy calculation of compatibility, dependency, compactness, suitability, and the violation of per capita demand. The output of these fuzzy calculations is a fuzzy decision matrix for each parcel with the size of $m \times n$, in which $m$ is the number of land-uses and $n$ is the number of criteria.

\subsubsection{The Neighborhood of Parcels}

The value of compatibility and dependency of each land-use is associated with land-uses of its neighboring parcels. Near parcels have more neighborhood effects on each other, and vice versa. Accordingly, the neighborhood is defined as near, relatively near, relatively far, far, very far, and non-neighbor. To determine the fuzzy weight of each group of neighbors, the $\alpha$ coefficient is used, which is defined as follows [21]:

$$
\alpha=\left\{\begin{array}{c}
1 d_{i j} \leq d_{\min }^{k} \\
\left(\frac{d_{\max }^{k}-d_{i j}}{d_{\max }^{k}-d_{\min }^{k}}\right)^{k} d_{\min }^{k}<d_{i j} \leq d_{\max }^{k} \\
0 d_{i j}>d_{\max }^{k}
\end{array}\right.
$$

where $d_{\text {min }}^{k}$ is the minimum distance that land-use $\mathrm{k}$ has the most effect on other land-uses, $d_{\text {max }}^{k}$ is the maximum distance that land-use $\mathrm{k}$ has the least effect on other land-uses, and $d_{i j}$ is nearest Euclidean distance between two parcels $i$ and $j$. For All land-uses, $d_{\text {min }}^{k}$ is considered zero. The value of $d_{\text {max }}^{k}$ is obtained from the radius of effect table that is provided by [40] and presented in Appendix A. The fuzzy weight values of each neighbor are defined based on $\alpha$ coefficient and are shown in Table 1 . 
Table 1. Linguistic values and their corresponding fuzzy numbers for neighborhood types.

\begin{tabular}{ccc}
\hline$\alpha$ Values & Linguistic Values & Corresponding Fuzzy Numbers \\
\hline$\alpha=0$ & Non-neighbor & $(0,0,0)$ \\
$0<\alpha \leq 0.2$ & Very far & $(0,0,0.3)$ \\
$0.2<\alpha \leq 0.4$ & Far & $(0.1,0.3,0.5)$ \\
$0.4<\alpha \leq 0.6$ & Relatively far & $(0.3,0.5,0.7)$ \\
$0.6<\alpha \leq 0.8$ & Relatively near & $(0.5,0.7,0.9)$ \\
$0.8<\alpha \leq 1.0$ & Near & $(0.7,1,1)$ \\
\hline
\end{tabular}

\subsubsection{Compatibility}

Urban land-uses in a neighborhood should not have negative effects on their activities [41]. Based on this fact, the relation among different land-uses in terms of compatibility can be categorized into several groups (Figure 2). To figure out the amount of compatibility of a land-use with the neighboring land-uses, a compatibility matrix offered by [21] is used. This matrix is extracted employing the Delphi method. Table 2 shows a part of the used compatibility matrix for two of the ten land-uses, namely residential and commercial. The full compatibility matrix is $38 \times 38$.

Table 2. A part of the compatibility matrix from [21], with linguistic values of compatibility between land-uses, i.e., highly incompatible (HI), moderately incompatible (MI), low / neutrally compatible (NC), moderately compatible (MC), and highly compatible (HC).

\begin{tabular}{cccccccc}
\hline & & \multicolumn{3}{c}{ Residential } & \multicolumn{2}{c}{ Commercial } \\
\cline { 3 - 8 } & & Low-Density & Moderate-Density & High-Density & Local & District & Regional \\
\hline \multirow{3}{*}{ Residential } & Low-Density & HC & & & & & \\
& Moderate-Density & MC & HC & & & & \\
& High-Density & MI & MC & HI & & & \\
\hline \multirow{3}{*}{ Commercial } & Local & HC & HC & HC & HC & & N \\
& District & N & MC & MC & N & MI \\
& Regional & N & N & N & N & MC \\
\hline
\end{tabular}

As it is shown in Figure 2, triangular fuzzy numbers are used to express different ratios of compatibility. By considering $\widetilde{\alpha}_{j}=\left(o_{j}, p_{j}, q_{j}\right)$ as the weight for neighboring land-uses which is obtained from Table 1, compatibility of the given parcel with respect to neighboring parcels $\left(\widetilde{C}_{i}\right)$ is calculated as follows:

$$
\widetilde{C}_{i}=\frac{\oplus_{j=1}^{N_{i}}\left(\widetilde{\alpha}_{j} \otimes \widetilde{C}_{i, j}\right)}{N_{i}}
$$

where $\widetilde{C}_{i, j}$ is compability between the land-uses of subject parcel $i$ and neighboring parcel $j$, and $N_{i}$ is the number of neighbors of the parcel $i$.

\subsubsection{Dependency}

A land-use can be dependent on other land-uses to supply its needs [25]. For example, residential-use is dependent on educational, medical and commercial uses to supply their needs. The dependency between land-uses can be estimated by linguistic variables, such as high dependency, moderate dependency, low dependency, moderate independency, and high independency. The dependency matrix offered by [40] is used to calculate the dependency of a land-use with the neighboring land-uses. The dependency of the given parcel with respect to neighboring parcels, $\widetilde{D}_{i}$, is calculated as follows: 


$$
\widetilde{D}_{i}=\frac{\oplus_{j=1}^{N_{i}}\left(\widetilde{\alpha}_{j} \otimes \widetilde{D}_{i, j}\right)}{N_{i}}
$$

where $\widetilde{D}_{i, j}$ is the dependency between the land-uses of the subject parcel $i$ and neighboring parcel $j$, and $\widetilde{\alpha}_{j}$ is the weight of neighboring land-use in parcel $j$.

\subsubsection{Compactness}

Some land-uses, such as residential, have the tendency to locate in the same neighborhood; this criterion is referred to as compactness. Compactness of the same land-uses can be considered as an evaluation criterion for land-use arrangement [2,22]. To calculate this criterion, the compactness parameter $(C P)$ is defined as follows:

$$
C P_{k}=\frac{N_{k}^{S}}{N_{k}^{T}}
$$

where $N_{k}^{S}$ is the number of the same neighbors of a land-use $k$, and $N_{k}^{T}$ is the total neighbors of land-use $k$.

According to Table 3, the linguistic variable of $C P$ takes the linguistic values: very low, low, medium, high, and very high.

Table 3. Linguistic values and their corresponding fuzzy numbers of compactness.

\begin{tabular}{ccc}
\hline Compactness Parameter $(\boldsymbol{C P})$ & Linguistic Values & Corresponding Fuzzy Numbers \\
\hline$C P<0.2$ & Very low & $(0,0,0.3)$ \\
$0.2 \leq C P<0.4$ & Low & $(0.1,0.3,0.5)$ \\
$0.4 \leq C P<0.6$ & Medium & $(0.3,0.5,0.7)$ \\
$0.6 \leq C P<0.8$ & High & $(0.5,0.7,0.9)$ \\
$0.8 \leq C P<1.0$ & Very high & $(0.7,1,1)$ \\
\hline
\end{tabular}

\subsubsection{Suitability}

Suitability criterion determines the compatibility between the land-use and its location [21,42]. The characteristics which are considered to calculate the suitability of the subject parcel, in accordance with [21], include: area, access type, number of vertices, mean slope, ownership type, sound and air pollution, resistance to change, and the difference between the size of the subject parcel edges. By taking into account the above-mentioned characteristics, the suitability of each parcel, with respect to each land-use, can be expressed with linguistic values, as shown in Table 4.

Table 4. Linguistic values and their corresponding fuzzy numbers of suitability.

\begin{tabular}{cc}
\hline Linguistic Values & Fuzzy Numbers \\
\hline Completely suitable & $(0,0,0.3)$ \\
Relatively suitable & $(0.2,0.4,0.6)$ \\
Relatively unsuitable & $(0.4,0.6,0.8)$ \\
Completely unsuitable & $(0.7,1,1)$ \\
\hline
\end{tabular}

\subsubsection{Per Capita Demand}

Per capita demand is a criterion that meets present and future needs of the study area. In order to apply this criterion in the MCDM model, according to the population of the study area, first, the amount of current per capita demand for each land-use is calculated. Then current per capita demand is compared 
with the optimum per capita of land-uses in study area obtained from [43]. For this purpose, per capita violation $(P C V)$ is determined and incorporated into the model. The $P C V$ is calculated as follows:

$$
P C V_{\mathrm{i}}=\left\{\begin{array}{l}
\frac{A_{i}^{\min }-A_{i}}{A_{i}^{\min }} \text { if } A_{i}<A_{i}^{\min }, \\
\frac{A_{i}-A_{i}^{\max }}{A_{i}^{\max }} \text { if } A_{i}>A_{i}^{\text {max }},
\end{array}\right.
$$

where $A_{i}^{\min }$ and $A_{i}^{\max }$ are the minimum and the maximum acceptable area which is obtained by multiplying the minimum and the maximum per capita of the land-use $i$, by the total population of the study area, and $A_{i}$ is the total area of the land-use $i$.

Fuzzification and assigning fuzzy numbers to different values of $P C V$ is done as shown in Table 5.

Table 5. Linguistic variables and the corresponding triangular fuzzy numbers for $P C V$.

\begin{tabular}{ccc}
\hline Per Capita Violation $(P C V)$ & Linguistic Values & Fuzzy Numbers \\
\hline$P C V<0.2$ & Very low & $(0.7,1,1)$ \\
$0.2 \leq P C V<0.4$ & Low & $(0.5,0.7,0.9)$ \\
$0.4 \leq P C V<0.6$ & Medium & $(0.3,0.5,0.7)$ \\
$0.6 \leq P C V<0.8$ & High & $(0.1,0.3,0.5)$ \\
$0.8<P C V$ & Very high & $(0,0,0.3)$ \\
\hline
\end{tabular}

\subsection{Ranking Urban Land-Uses for Each Parcel}

After calculating of the decision-making criteria, the rank of each land-use is determined for the subject parcel. Determination of land-use priorities with fuzzy TOPSIS are composed of different steps. In the following, each step is explained in detail.

In the first step, the decision matrix of each parcel must be normalized in order to limit their values between zero and one, and be compatible with each other. Triangular fuzzy numbers in the decision matrix, which are shown as $\left(a_{i j}, b_{i j}, c_{i j}\right)$, can be normalized as follows [34]:

$$
\widetilde{r}_{i j}=\left(\frac{a_{i j}}{c_{i j}^{+}}, \frac{b_{i j}}{c_{i j}^{+}}, \frac{c_{i j}}{c_{i j}^{+}}\right), c_{i j}^{+}=\max _{i} c_{i j}
$$

In the second step, the fuzzy weighted decision matrix is obtained by multiplying the fuzzy weights by the fuzzy decision matrix:

$$
\widetilde{V}=\left[\widetilde{v}_{i j}\right], \widetilde{v}_{i j}=\widetilde{r}_{i j} \otimes \widetilde{w}_{j}
$$

where $\widetilde{w}_{j}$ is the fuzzy weight of the criterion $j, \widetilde{r}_{i j}$ is fuzzy value of the criterion $j$ for the land-use $i$, and $\widetilde{v}_{i j}$ is weighted fuzzy value of the criterion $j$ for the land-use $i$. The importance of each criterion is selected by experts between Very low $(0,0,0.3)$, Low $(0.1,0.3,0.5)$, Medium $(0.3,0.5,0.7)$, High $(0.5,0.7$, $0.9)$, and Very high $(0.7,1,1)$. The final aggregated weights of criteria (Table 6$)$ are obtained by fuzzy simple additive weighting [44].

Table 6. Aggregated fuzzy weights of the criteria.

\begin{tabular}{cccccc}
\hline \multirow{2}{*}{ Criteria } & \multicolumn{4}{c}{ Experts } & $\begin{array}{c}\text { Aggregated } \\
\text { Weights }\left(\widetilde{w}_{j} \text { ) }\right.\end{array}$ \\
\cline { 2 - 5 } & E1 & E2 & E3 & E4 & \\
\hline Compatibility & $(0.5,0.7,0.9)$ & $(0.3,0.5,0.7)$ & $(0.7,1,1)$ & $(0.5,0.7,0.9)$ & $(0.50,0.75,0.87)$ \\
Dependency & $(0.7,1,1)$ & $(0.5,0.7,0.9)$ & $(0.1,0.3,0.5)$ & $(0.5,0.7,0.9)$ & $(0.45,0.67,0.82)$ \\
Compactness & $(0,0,0.3)$ & $(0.1,0.3,0.5)$ & $(0,0,0.3)$ & $(0.3,0.5,0.7)$ & $(0.10,0.20,0.45)$ \\
Suitability & $(0.3,0.5,0.7)$ & $(0.1,0.3,0.5)$ & $(0.5,0.7,0.9)$ & $(0.3,0.5,0.7)$ & $(0.30,0.50,0.70)$ \\
PCV & $(0.1,0.3,0.5)$ & $(0.7,1,1)$ & $(0.1,0.3,0.5)$ & $(0,0,0.3)$ & $(0.22,0.40,0.57)$ \\
\hline
\end{tabular}


In the third step, positive and negative ideal solutions are obtained. A vector comprising the maximum value for positive criteria and minimum value for negative criteria is considered as the positive ideal solution, and vice versa. A vector comprising the minimum value for positive criteria and maximum value for negative criteria is considered as the negative ideal solution. To obtain these vectors, the decision matrix is ordered descending and first-row values are selected as the positive and last row values are selected as the negative ideal solution. These ideal solutions $\left(A^{+}, A^{-}\right)$, are represented as:

$$
\begin{aligned}
& A^{+}=\left(\widetilde{v}_{1}^{+}, \widetilde{v}_{2}^{+}, \ldots, \widetilde{v}_{n}^{+}\right) \\
& A^{-}=\left(\widetilde{v}_{1}^{-}, \widetilde{v}_{2}^{-}, \ldots, \widetilde{v}_{n}^{-}\right)
\end{aligned}
$$

where $\widetilde{v}_{1}^{+}, \widetilde{v}_{2}^{+}, \ldots, \widetilde{v}_{n}^{+}$are maximum and $\widetilde{v}_{1}^{-}, \widetilde{v}_{2}^{-}, \ldots, \widetilde{v}_{n}^{-}$are minimum values of criteria 1 to $n$.

In the fourth step, the distance of each alternative from ideal solutions can be calculated as:

$$
\begin{aligned}
& d_{i}^{+}=\sum_{j=1}^{n} d\left(\widetilde{v}_{i j}, \widetilde{v}_{j}^{+}\right) \\
& d_{i}^{-}=\sum_{j=1}^{n} d\left(\widetilde{v}_{i j}, \widetilde{v}_{j}^{-}\right)
\end{aligned}
$$

where $d_{i}^{+}$is the distance from the positive ideal solution, and $d_{i}^{-}$is the distance from the negative ideal solution.

Finally, in the fifth step, the closeness coefficient $\left(C C_{i}\right)$ is calculated as follows to detemine the ranking order of the land-uses as alternatives:

$$
C C_{i}=\frac{d_{i}^{-}}{d_{i}^{+}+d_{i}^{-}}
$$

The land-uses with higher closeness coefficients have a higher order in the ranking.

\subsection{Allocating Land-Uses to Urban Parcels}

The urban land-use allocation goal is to achieve an optimal arrangement of land-uses using determined priorities which are proposed by the model. Considering the defined constraints, the land-use that gains the first priority in the subject parcel is allocated to that parcel. To that end, first, a random arrangement of land-uses is produced taking into account the defined constraint. Then, in an iterative process, the first priority of land-uses for each parcel is allocated to that parcel. During the iterative process of the land-use allocation, only the land-uses are considered that are compatible with all constraints. In the case no land-use is found compatible with all constraints, the land-use is chosen that is compatible with the first three constraints and has the lowest constraint violation in the fourth constraint (Equation (14)). Constraints are explained in Section 4.3. Figure 3 shows the process of allocating land-uses to urban parcels. 


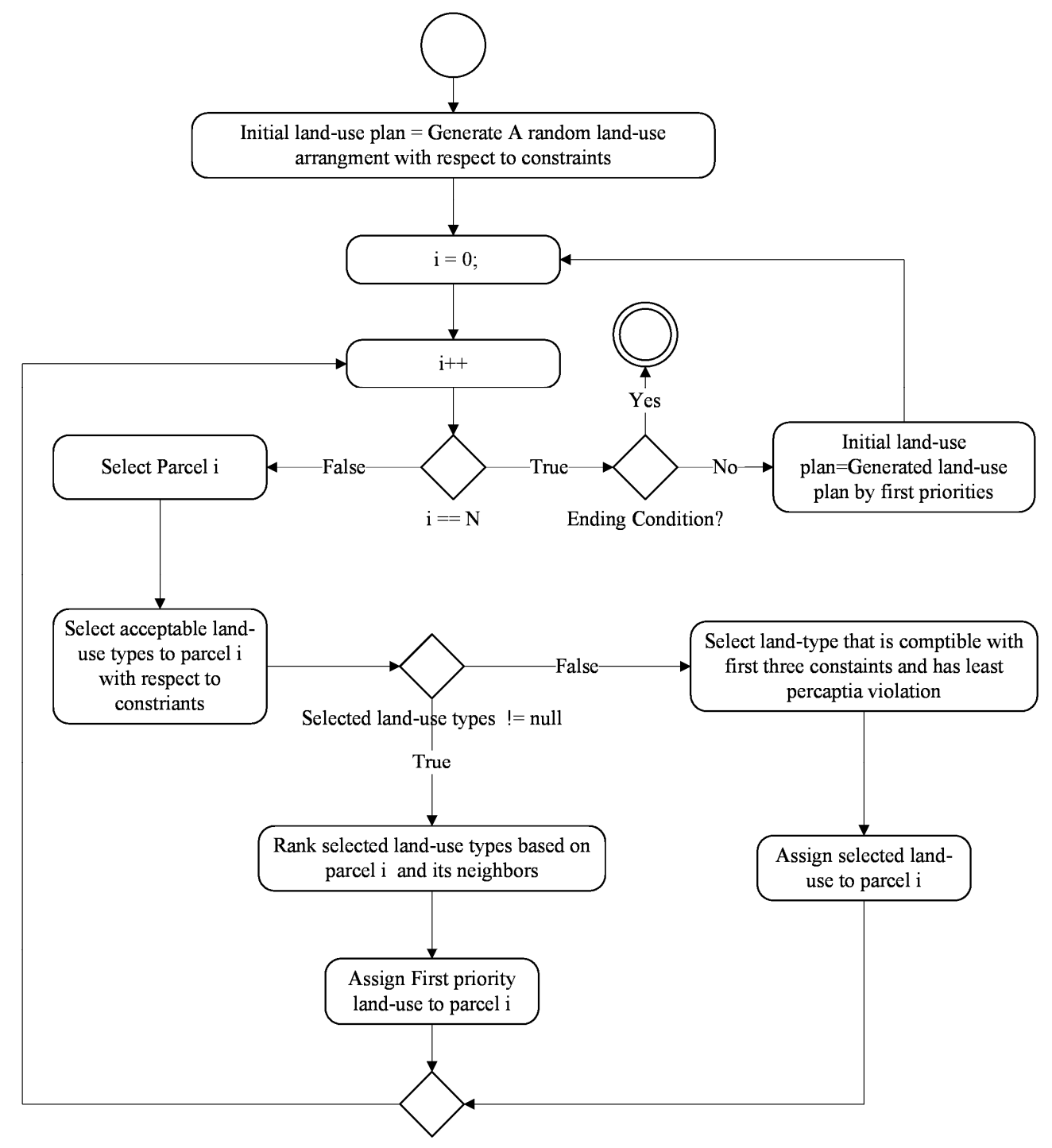

Figure 3. Land-use allocation process.

\section{Implementation and Analytics}

\subsection{Study Area}

Given that the proposed model is designed on the basis of urban parcels, the land-use map of region 7, district 1 of Tehran at the parcel level on the scale 1:2000 is used to evaluate the model. Figure 4 shows the urban parcels and their land-uses in the study area. In this map, urban parcels are displayed individually and are not clustered into blocks. The number of parcels in the study area is 2709 . The parcels layer is applied in the form of vector data and 38 urban land-use types are defined with respect to the three service levels of local, distinct, and regional. The existence of various land-uses in different service levels is the significant points of this study area which complicates the issue of urban land-use management. 


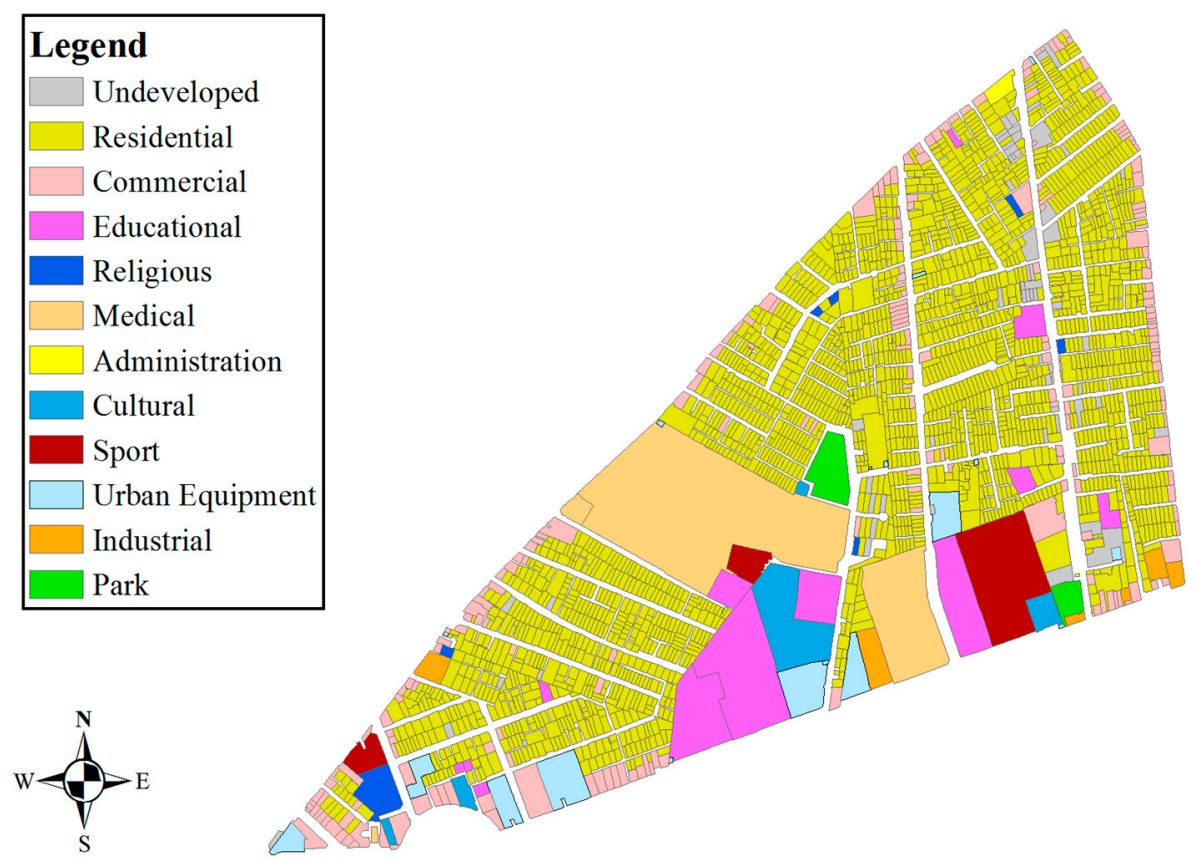

Figure 4. The urban parcels and their land-uses in the study area.

\subsection{GA for Urban Land-Use Allocation}

In order to evaluate the results of the proposed land-use allocation process, an optimization technique is used to solve ULUP. The GA as a most common optimization technique in land-use planning $[2,23,45,46]$, and is applied to optimize ULUP. The optimal land-use arrangement has been obtained through GA by defining four objective functions and applying four defined constraints. The first four criteria which are used in the proposed model (i.e., compatibility, dependency, suitability, and compactness) are used to define objective functions, and the last criterion (i.e., the violation of per capita) is used as a constraint. Due to the use of quantitative values in solving the optimization problem with the GA, qualitative values of compatibility and dependency between two land-use types are quantified. The quantification of these criteria values follows Table 2 of [21]. The objective functions for each criterion are defined as follows:

$$
\begin{gathered}
F 1=\left\{\frac{1}{n}\left(\sum_{i=1}^{n} \frac{1}{n_{i}} \sum_{j=1}^{n_{i}} \alpha_{i j} \times C_{i j}\right)+\min \sum_{j=1}^{n_{i}} \alpha_{i j} \times C_{i j}\right\} \\
F 2=\left\{\frac{1}{n}\left(\sum_{i=1}^{n} \frac{1}{n_{i}} \sum_{j=1}^{n_{i}} \alpha_{i j} \times D_{i j}\right)+\min \sum_{j=1}^{n_{i}} \alpha_{i j} \times D_{i j}\right\} \\
F 3=\left\{\frac{1}{n}\left(\sum_{i=1}^{n} S_{i}\right)+\min S_{i}\right\} \\
F 4=\frac{1}{n}\left(\sum_{i=1}^{n} \frac{\operatorname{sim} m_{i}}{n_{i}}\right)
\end{gathered}
$$

In Equations (22)-(25), $\mathrm{i}$ indicates the subject parcel and $\mathrm{j}$ indicate its neighbors; $n$ is the number of the parcels, and $n_{i}$ is the number of neighboring parcels of the subject parcel; $C_{i j}$ is the quantified value of the compatibility between two land-uses of parcels $i$ and $j ; D_{i j}$ also is the quantified value of the dependency between two land-uses of parcels $i$ and $j$; $S_{i}$ is suitability of the parcel $j$; and $\operatorname{sim}_{i}$ is the number of neighboring parcels with the similar land-use of the subject parcel. 
The second part in Equations (22)-(24), is used to maximize the minimum value of the criteria in the arrangement. This part of the equations could improve the criteria value in the parcels having the minimum value in comparison with their neighbors.

We have used the simple additive weighting (SAW) method to achieve the overall objective function for the GA as follows:

$$
\text { maximize } F=w_{1} \times F_{1}+w_{2} \times F_{2}+w_{3} \times F_{3}+w_{4} \times F_{4},
$$

The overall objective function weights $\left(w_{1}, w_{2}, w_{3}, w_{4}\right)$ are obtained by defuzzification of the aggregated fuzzy weights, which is presented in Table 6.

To implement the GA, the land-use map of the study area is considered as a chromosome in which each of the parcels indicates its genes. The initial population is created randomly by taking into account the first three types of the constraints. The crossover step is defined as dividing the two selected land-use maps, as two parent solutions, into three segments, and generating two offspring solutions by randomly combining the segments of the two selected parents. The mutation step is defined as selecting 10 percent of the parcels, and changing randomly their allocated land-uses by taking into account the first three types of the constraints.

\subsection{Constraints}

According to the study area, four types of constraints are considered to allocate the land-uses to urban parcels by the proposed model, which are defined as follows:

1. Constraints related to parcel area: this type of constraint determines the minimum and the maximum parcel area for each land-use. These constraints prevent the allocation of the land-uses to the parcels that are not suitable regarding their area for those land-use types. The parcel area ranges for each land-use are extracted from [47].

2. Constraints related to access types: according to the development pattern of district 7 of Tehran [48], urban land-use access types are determined. To reach the optimal land-use arrangement, in such a way that it will be consistent with the development pattern of the district, these land-use access types are considered as constraints in ULUP.

3. Constraints related to unchangeable land-uses: some trans-regional and religious land-uses are not changeable. These types of land-uses are considered as unchangeable land-uses in ULUP.

4. Constraint related to urban land-uses per capita: This constraint controls the amount of per capita demand for each land-use in the study area. Minimum and maximum per capita demand for each land-use type are determined and applied in ULUP [47].

In the GA for urban land-use allocation, to avoid creating an infeasible solution, the first three types of constraints are checked in the initial solution generation, crossover, and mutation steps. The fourth constraint is used as a penalty function for infeasible solutions [49]. In order to apply the forth constraints, the objective function is defined as follows:

$$
F=\left\{\begin{array}{c}
F \text { if } C V=0, \\
F_{\text {min }}+C V \text { otherwise. }
\end{array}\right.
$$

where $F_{\min }$ is the overall objective function value of the worst feasible solution in the population, and $C V$ is the fourth constraint violation which is calculated as follows:

$$
\mathrm{CV}=\sum_{i=1}^{m} \mathrm{PCV}_{i}
$$

where $\mathrm{m}$ indicates the number of land-use types, and $P C V_{i}$ is per capita violation of the land-use $i$, which is calculated by Equation (14). 


\subsection{Parameters Setting}

To obtain the results of proposed land-use allocation process, the parameters such as the number of iterations, population size or mutation rate are adjusted by means of several executions. The number of iterations of the land-use allocation process is set to 30. In the GA, the population size is set to 100 and the number of generations is set to 100. Additionally, the crossover and mutation rate is set, respectively, to $60 \%$ and $40 \%$, and binary tournament selection is used to select parent solutions.

\section{Results and Discussion}

In this section, first, the results of land-use ranking, and then the results of defined process for land-use allocation are presented and discussed.

\subsection{Results of Urban Land-Use Rankings}

According to the proposed model, in order to prioritize urban land-uses, by considering different land-uses, evaluation criteria are calculated for each of the urban parcels. Figure 5 shows the defuzzified values of suitability, compatibility, dependency, and compactness for the current land-uses in the study area. In this figure, higher values show a better condition. As shown in this figure and according to Figure 4, compactness of residential parcels has a good situation. The reason is that these parcels are located next to each other. In terms of dependency, parcels with residential use have less dependency on each other.
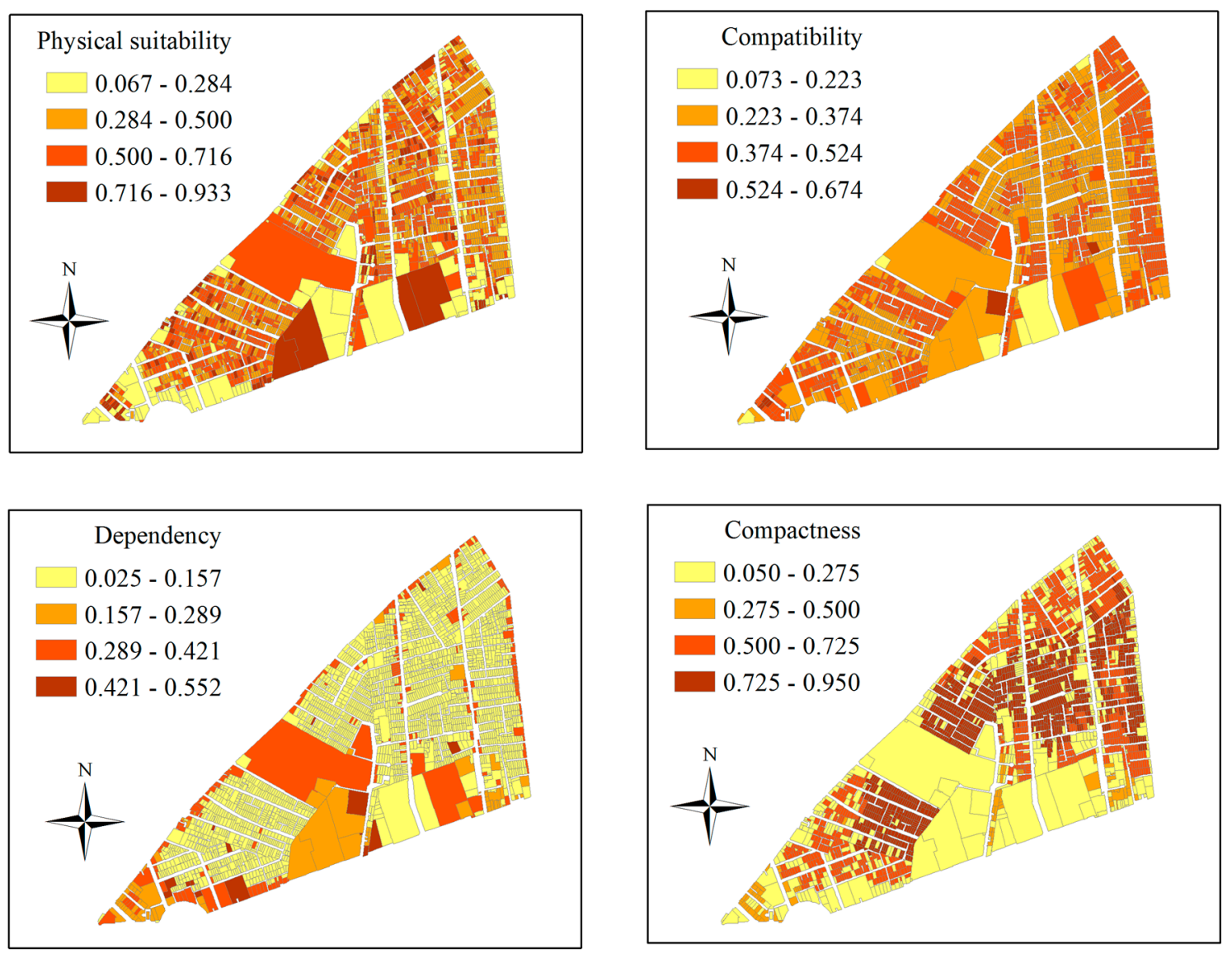

Figure 5. Defuzzified land-use evaluation criteria for current land-uses on the study area.

After calculation of the fuzzy values for all criteria, ranking orders of land-uses for each parcel are achieved by fuzzy TOPSIS. Figure 6 shows the rank of the current land-uses in the study area. Based on the calculated criteria values for each parcel, the current land-uses of the urban parcels are 
evaluated and ranked among all of the land-uses. These ranking orders can be used as an appropriate indicator for assessing the current land-use of a parcel. If the current land-use of a parcel wins the first place in the ranking order, this land-use is the most suitable for the parcel. Otherwise, there will be one or more land-uses that are more suitable for this parcel.

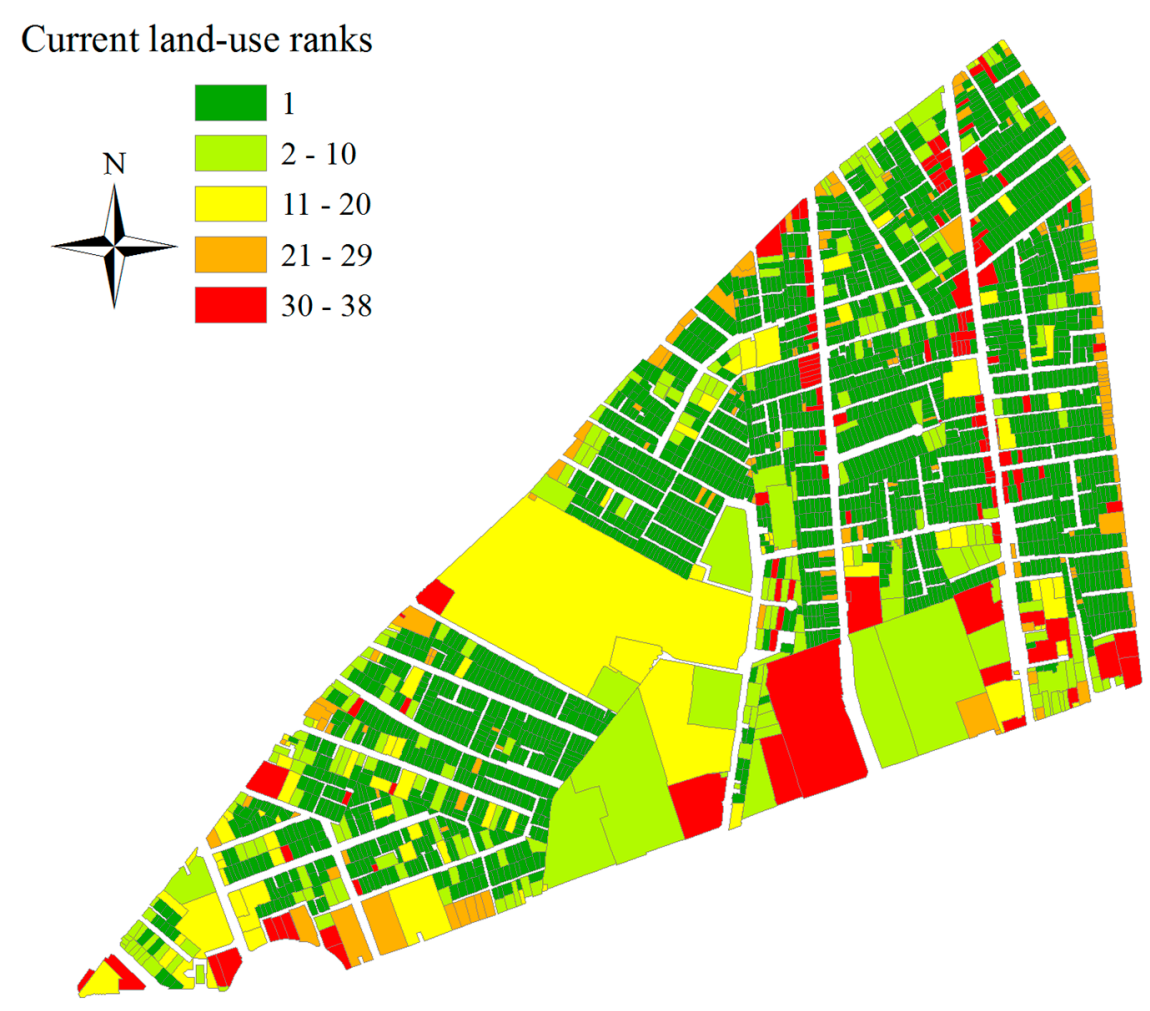

Figure 6. Current land-use ranks.

In terms of the number of urban parcels, $77.2 \%$ of land-uses within the study area have the first priority for their parcels. However, according to Figure 6, most parcels with high areas which have been allocated to uses such as industrial, health, and educational, miss the first priority for their own uses. In terms of the area, the parcels having a land-use with the first priority include just $44.6 \%$ of the total area of the parcels in the district.

Figure 7 shows the cumulative diagram of the number of the parcels for each land-use in different ranking orders. For example, as shown in Figure $7 \mathrm{~A}, 70 \%$ of parcels having an educational land-use are ranked sixth or lower. According to Figure $7 \mathrm{C}$, industrial use has the worst situation among all the land-uses, and in the best case, this land-use is ranked as 34th for the parcels having industrial use. The reasons behind this fact can be low compatibility and dependency with other land-uses, and lack of necessity to industrial use in this urban area based on the per-capita criterion. Residential land-use has the best situation among all land-uses. The reasons behind this fact can be high compactness of residential use, and the need to provide this land-use per capita in the study area. 


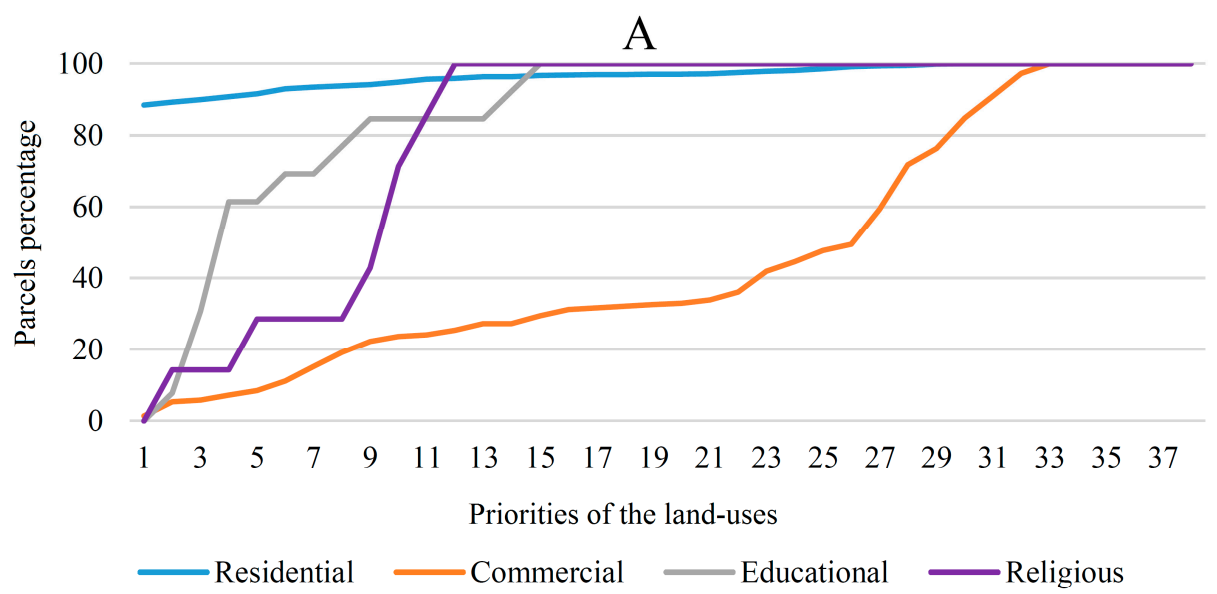

B

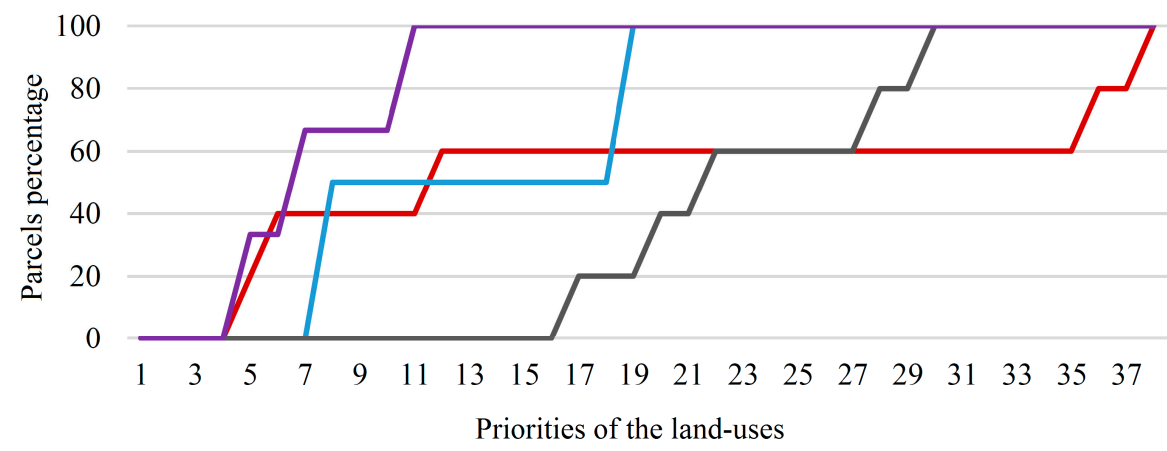

$\longrightarrow$ Medical $\longrightarrow$ Administration Cultural $\longrightarrow$ Sport

$\mathrm{C}$

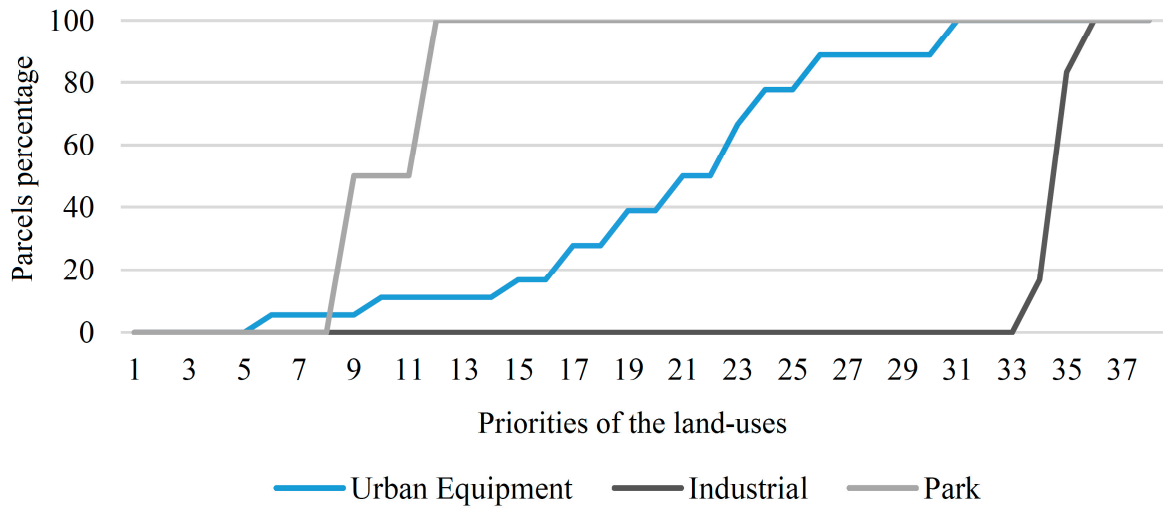

Figure 7. Diagram of the current land-uses percentage in different priorities (the vertical and horizontal axes show the percentages and the different priorities of the land-uses respectively).

In order to make a detailed analysis of the results, one of the parcels whose land-use in ranking lacks a suitable position has been chosen and investigated with more details. For a parcel specified in Figure 8, evaluation criteria have been calculated for all land-uses and a section of decision matrix is shown in Table 7. 
Current land-use ranks
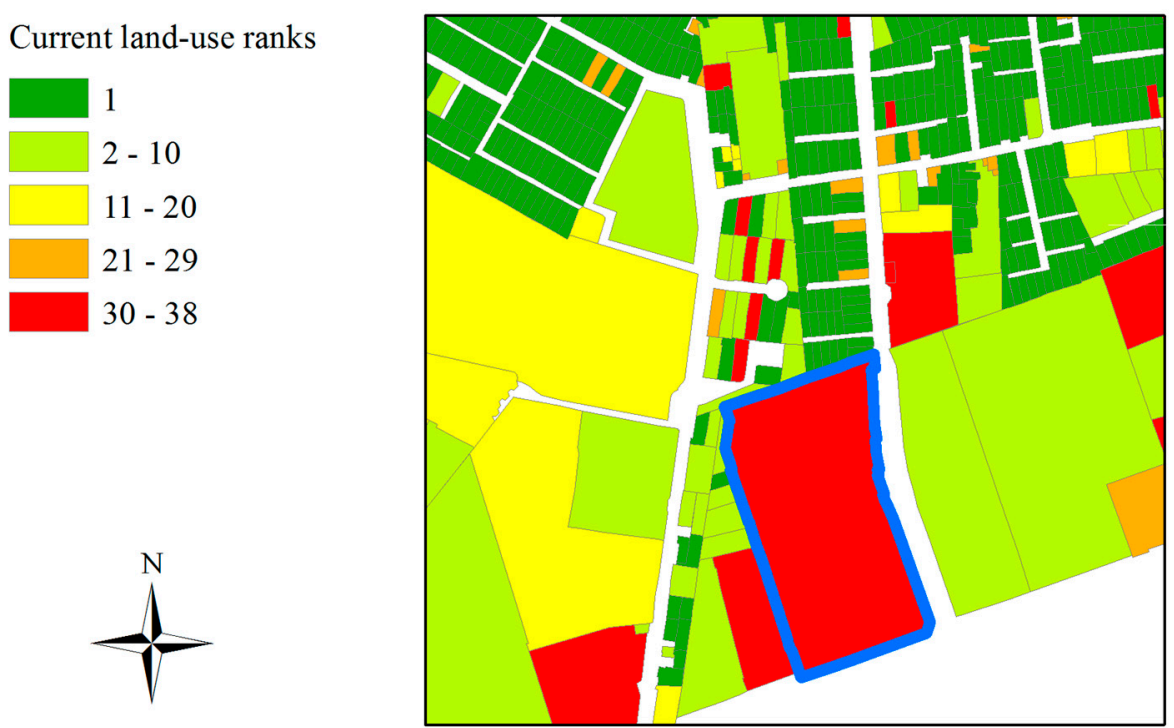

Figure 8. A selected urban parcel.

Table 7. A section of the decision matrix of an urban parcel.

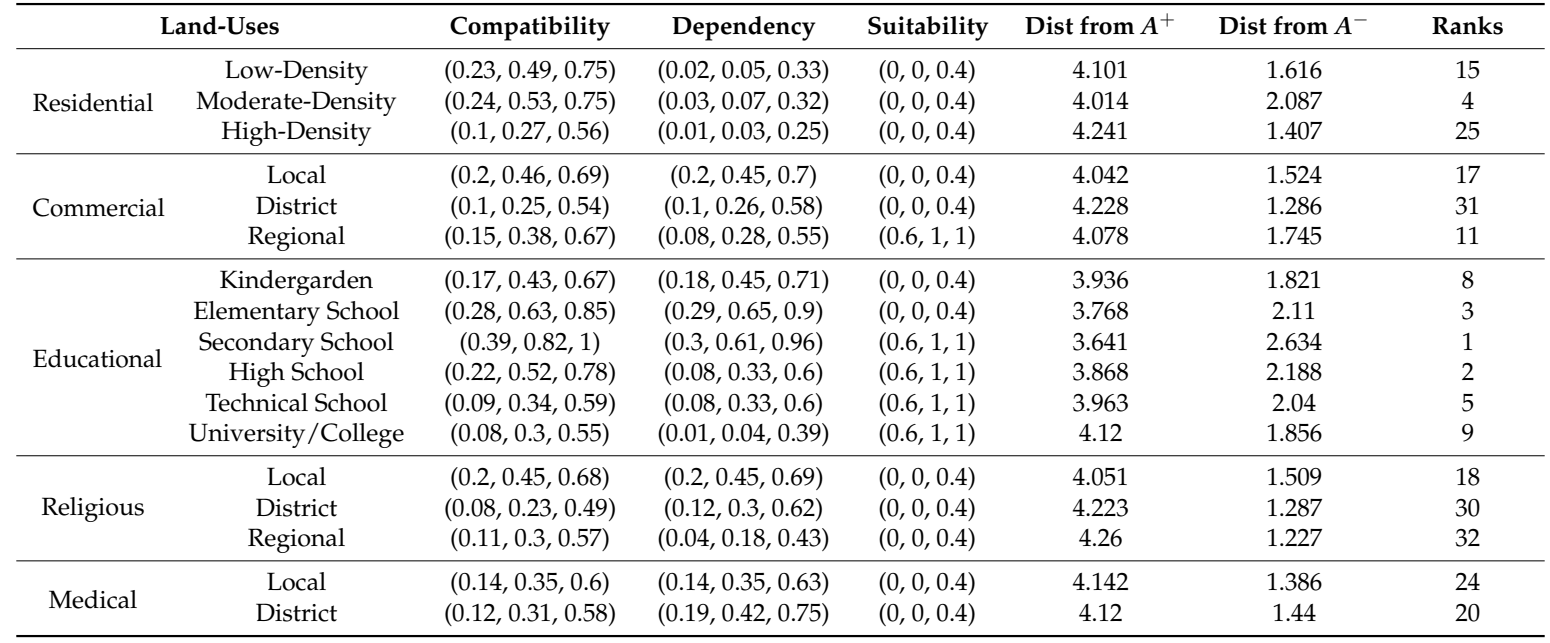

As illustrated in Table 7, educational use at secondary school level is allocated the first rank in this subject parcel. According to criteria values in Table 7, educational use at the level of secondary school has high compatibility and dependency with the neighbor uses of the subject parcel. Due to the allocation of the fuzzy number $(0.7,1,1)$ for the per-capita criterion, it can be concluded that the per capita of educational use at the level of secondary school is deficient in the study area. The compactness criterion value is low due to the lack of educational use in the neighborhood of the subject parcel. This land-use has a minimum distance from positive ideal solution and maximum distance from negative ideal solution among all land-uses. The current land-use of the subject parcel is medical at the regional level. According to Table 7, medical use at the regional level has low compatibility and dependency with the neighbor uses of the subject parcel, and also received a low mark in terms of the suitability and compactness criteria. Based on the per capita criterion value of this land-use, it can be stated that the study area is situated in a good condition in terms of medical use per capita and this land-use seems to be unnecessary for the subject parcel. As a result, the rank of this land-use for the subject parcel is 37 and is considered among the last priorities for this parcel. 


\subsection{Results of Urban Land-Use Allocation}

After executing the proposed land-use allocation process and GA, the output maps are obtained as shown in Figure 9. Due to using previously-defined constraints, such as constraints related to the parcel area and access types, the land-use layouts are in accordance with reality, and each of the land-uses is allocated in their appropriate parcels and street types. The per-capita constraint also controls the area of each of the land-uses and hence, on the final layout, each land-use is allocated based on the necessity of the study area. As well as constraints related to unchangeable land-uses preventing the changing of such land-uses. For instance, medical trans-regional land-use at the center of the study area is not changed through the land-use allocation process. Constraints are obtained from the development pattern of district 7 of Tehran $[47,48]$ and are necessary to generate a valid land-use plan. However, considering less constraint gives rise to greater degrees of freedom in the generation of land-use plans and the values of criteria can be further improved in the process of optimization.
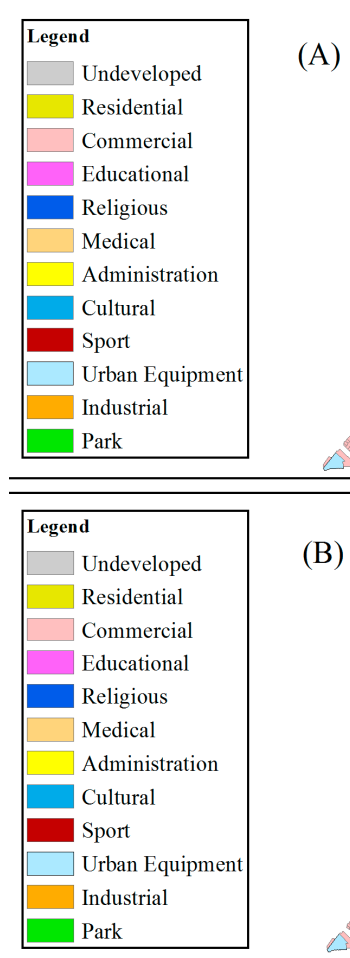

(A)

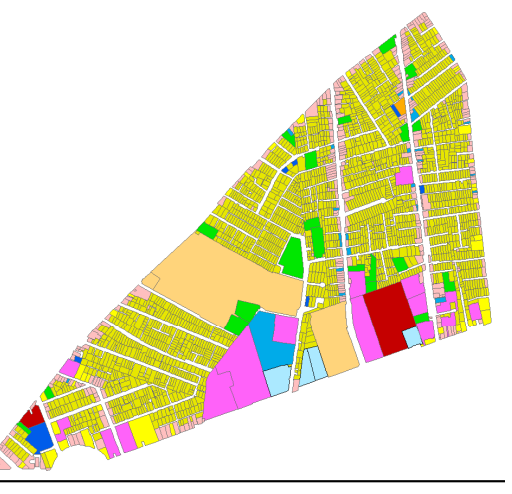

(B)

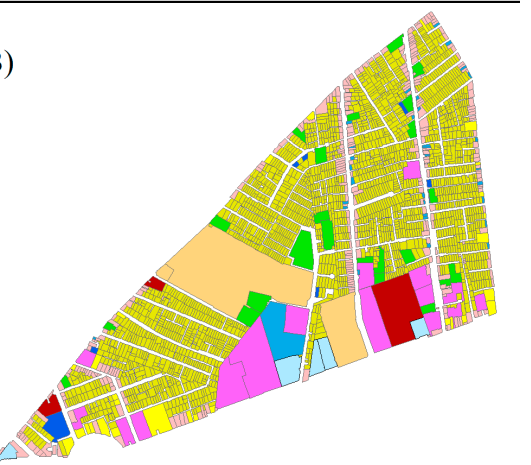

Figure 9. Land-use arrangements. (A) The output of the proposed land-use allocation process. (B) The output of the GA.

Figure 10 shows the overlap percentage of each solution with the previous one, for proposed and GA land-use allocation process. As shown in Figure 10, solutions of the proposed process from the sixth iteration to the next have reached a relative convergence and have obtained an overlap percentage above $95 \%$ with their previous solutions. It should be noted that, with the execution of the proposed process in a high number of iterations, the land-use of some parcels (about 3\%) falls in a recurring loop. In other words, the allocation of some land-uses cyclically change in the parcel. For this reason, the generated plans never reach the $100 \%$ overlap with their previous plan. In the GA land-use allocation process, overlap percentages of the solutions have reached a relative stability from iteration 60 to the next. Comparing the overlap percentage results of the land-use allocation processes, it is obvious that the convergence of the proposed process is much faster. As shown in Table 8, the overlap percentage of final solutions for each process shows that the final solution of two processes tend to converge to the same solution. The overlapping difference between final land-use layouts of proposed and GA land-use allocation process is less than $5 \%$ (Table 8). 
(a)

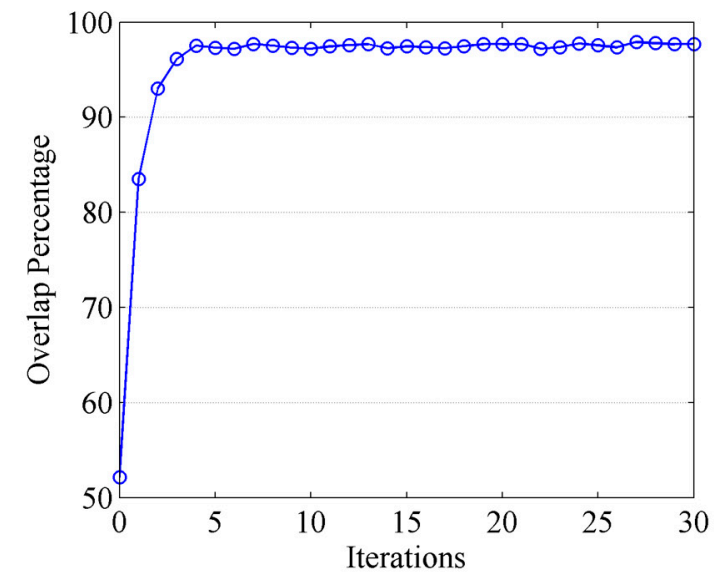

(b)

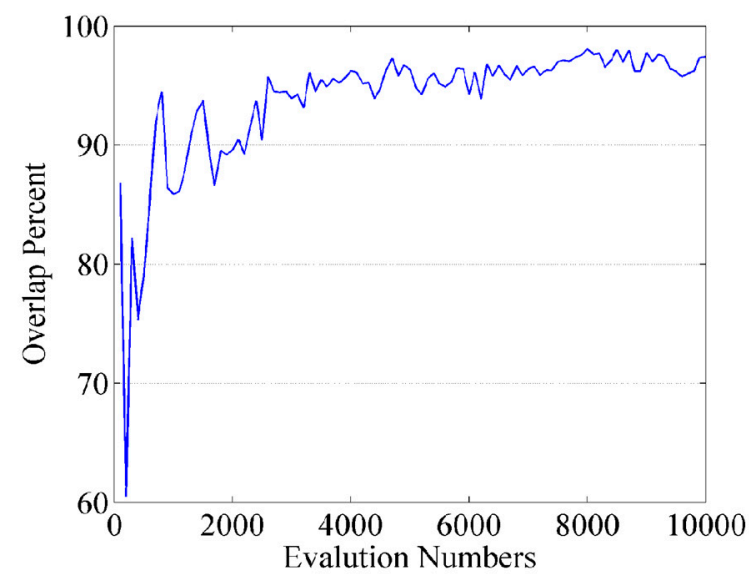

Figure 10. Land-use arrangement overlaps in each iteration with previous iteration result. (a) Proposed process. (b) GA.

Table 8. Overlap percentage of land-use arrangements obtained from proposed process, GA and the current status.

\begin{tabular}{cccc}
\hline & Current Status & Proposed Process & GA \\
\hline Current Status & 100 & 87.08 & 86.97 \\
proposed process & 87.08 & 100 & 95.24 \\
GA & 86.97 & 95.24 & 100 \\
\hline
\end{tabular}

The values shown in Table 8 are achieved by averaging the results of 10 different executions. The results of the proposed process under various executions by different random initial land-use arrangements indicate that there are no meaningful differences in the final arrangements. Thus, we can say that the model is not dependent on the initial random arrangements and the possibility of the model to fall in a local optimum is low.

According to Table 8 , the land-use of about $87 \%$ of parcels in the study area are matching with optimized plans. In addition, in Figure 6, it is shown that most parcels (about 72\%) have the first rank land-use. As a result, we can say that the result of ranking and allocating land-uses are compatible with each other.

Figure 11 shows the values of the overall objective function of land-use allocation with the proposed process and the GA in different iterations. As seen in Figure 11, in terms of the overall objective functions, the two allocation processes have converged almost to the same value. Additionally, Table 9 shows the values of all objective functions in the two allocation processes and the current status. These obtained values show an improvement of all criteria in the output map of the two allocation processes compared to the current status. 
(a)

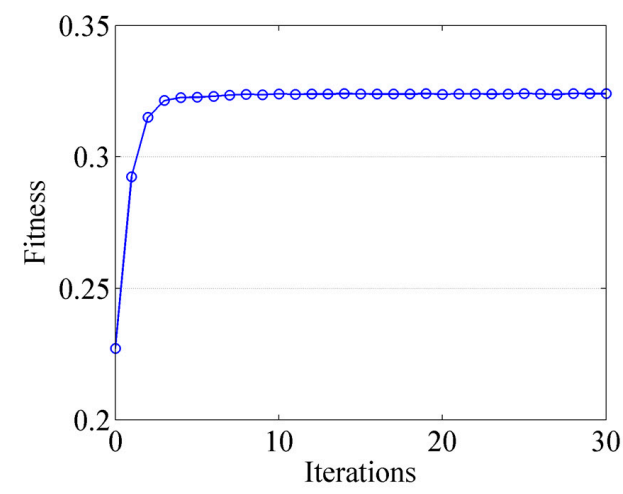

(b)

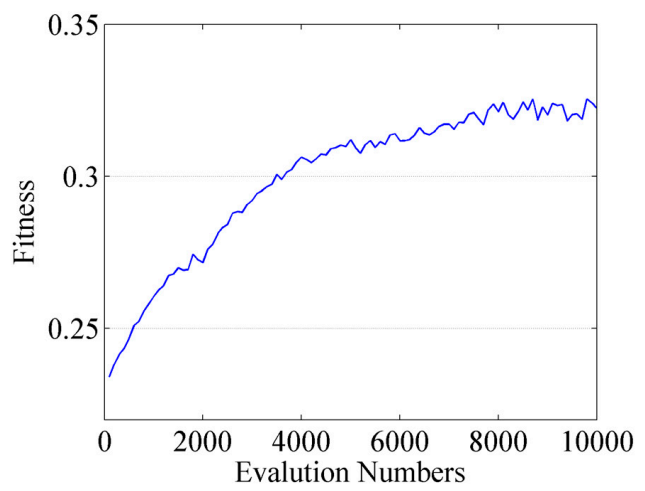

Figure 11. Fitness values of the proposed process (a) and GA (b).

Table 9. Objective values of the proposed and GA land-use allocation processes compared with the current status.

\begin{tabular}{cccccc}
\hline & Obj. 1 & Obj.2 & Obj. 3 & Obj. 4 & Weighted Sum \\
\hline current status & 0.1493 & 0.0409 & 0.3318 & 0.6127 & 0.2837 \\
$\begin{array}{c}\text { Proposed } \\
\text { process }\end{array}$ & 0.1770 & 0.0410 & 0.3996 & 0.6906 & 0.3271 \\
GA & 0.1642 & 0.0404 & 0.4714 & 0.6139 & 0.3224 \\
\hline
\end{tabular}

A comparison of the execution time of two land-use allocation processes represents a relatively low convergence speed of the GA optimization method in ULUP. As it can be seen in Figures 10 and 11, the proposed process, that is designed based on the proposed method, compared to the GA reaching convergence much faster and stabilizing in only 10 iterations. Both processes have been executed in a computer system with an Intel Core i5-4200U processor, and 4 GB of RAM. The execution time of 30 iterations in the proposed process on average was $95.3 \mathrm{~s}$, while the execution time of the GA with a population size of 100 and iteration of 100 on average was $1844 \mathrm{~s}$, which is meaningfully long compared to the proposed process. The proposed process, with a high-speed response, can be programmed as part of a PSS. Therefore, planners will be able to view changes for the proposed land-use of the subject parcels almost instantaneously by changing the land-use of one or more parcels.

\section{Conclusions}

Prioritization of the land-uses for each parcel alongside an urban land-use optimization process allows urban planners to have not only the optimal land-use for each parcel, but also a ranked suite of alternative land-uses for the parcel. This capability, in the form of an urban land-use planning support system, provides urban planners a suite of ranked land-use alternatives that, if needed, they can select another appropriate alternative land-use for each parcel. Accordingly, the main purpose of this study is to provide for such a model based on fuzzy multi-criteria decision-making. The criteria considered in the proposed model includes neighborhood effects, such as compatibility, dependency, compactness, suitability, and per capita demand. Due to the approximate nature of the most factors used to determine the value of these criteria, fuzzy computing is employed for modeling and determining the values of these criteria. Additionally, fuzzy TOPSIS is applied to rank the land-use types for each parcel. Due to the use of 38 different land-use types and by considering different service levels to determine the neighborhood of each land-uses, prioritization and allocation results of the proposed model is more consistent with reality. The implementation of this model on the spatial data of the study area showed that in $77.2 \%$ of the parcels the current land-uses have the first priorities for their parcel. As a result, in $22.8 \%$ of the parcels, the current land-uses do not have the first priorities and have the potential for change. In order to evaluate the capabilities of the proposed model in urban land-use allocation, 
a land-use allocation process is defined. The results of the proposed process (i.e., allocating based on the first land-use priority of each parcel) show that in an iterative process, urban land-use allocation is also done well and significant improvements are shown in the defined objective functions. For the sake of comparison, the GA is considered as an independent method for urban land-use arrangement optimization. The result comparison between the proposed process with the GA showed the high convergence speed of the proposed process. The GA converged to the same results in a relatively longer time. Finally, the proposed model can be used as a recommender system that can assist experts and urban planners along with allocating appropriate land-uses for different urban parcels by providing suitable alternatives for the current land-uses. The proposed model, with presenting the land-use ranking for each urban unit, can improve the PSS capabilities in allocating suitable land-uses to each unit of the urban land-use layout. In future research, the proposed model can be used to determine the strategies of each agent in an agent-based modeling of the various stakeholders involved in urban land-use planning. Each of the agents, in accordance with their preferences, can try to improve one or several specified criteria. By determining various weights for criteria, different strategies may be created for agents with different preferences.

Author Contributions: Jamshid Maleki and Zohreh Masoumi conceived and designed the methodology; Jamshid Maleki implemented the methodology; Farshad Hakimpour was acting as supervisor and revised the proposed methodology; Jamshid Maleki wrote the draft paper; Farshad Hakimpour and Zohreh Masoumi have critically revised and extended the paper.

Conflicts of Interest: The authors declare no conflict of interest.

\section{Appendix A}

Table A1. Land-use types and their radius of effects [40].

\begin{tabular}{|c|c|c|c|}
\hline No. & \multicolumn{2}{|c|}{ Land-use Types } & Radius of Effect \\
\hline 1 & \multirow{3}{*}{ Residential } & Low-Density & 50 \\
\hline 2 & & Moderate-Density & 100 \\
\hline 3 & & High-Density & 450 \\
\hline 4 & \multirow{3}{*}{ Commercial } & Local Level & 150 \\
\hline 5 & & District Level & 400 \\
\hline 6 & & Regional Level & 1000 \\
\hline 7 & \multirow{6}{*}{ Educational } & Kindergarten & 500 \\
\hline 8 & & Elementary School & 800 \\
\hline 9 & & Secondary School & 1200 \\
\hline 10 & & High School & 2000 \\
\hline 11 & & Technical School & 2000 \\
\hline 12 & & University/College & 2000 \\
\hline 13 & \multirow{3}{*}{ Religious } & Local Level & 150 \\
\hline 14 & & District Level & 500 \\
\hline 15 & & Regional Level & 750 \\
\hline 16 & \multirow{3}{*}{ Medical } & Local Level & 250 \\
\hline 17 & & District Level & 750 \\
\hline 18 & & Regional Level & 1500 \\
\hline 19 & \multirow{3}{*}{ Administration } & Local Level & 50 \\
\hline 20 & & District Level & 500 \\
\hline 21 & & Regional Level & 750 \\
\hline 22 & \multirow{3}{*}{ Cultural } & Local Level & 150 \\
\hline 23 & & District Level & 500 \\
\hline 24 & & Regional Level & 750 \\
\hline 25 & \multirow{3}{*}{ Sport } & Local Level & 250 \\
\hline 26 & & District Level & 750 \\
\hline 27 & & Regional Level & 2000 \\
\hline 28 & \multirow{3}{*}{ Urban Equipment } & Local Level & 150 \\
\hline 29 & & District Level & 500 \\
\hline 30 & & Regional Level & 1000 \\
\hline 31 & \multirow{4}{*}{ Industrial } & Local Level & 150 \\
\hline 32 & & District Level & 500 \\
\hline 33 & & Regional Level & 750 \\
\hline 34 & & Industrial Complex & 1500 \\
\hline 35 & \multirow{3}{*}{ Park } & Local Level & 350 \\
\hline 36 & & District Level & 750 \\
\hline 37 & & Regional Level & 1000 \\
\hline 38 & Vacant Land & & 0 \\
\hline
\end{tabular}




\section{References}

1. Berke, P.; Kaiser, E.J. Urban Land Use Planning; University of Illinois Press: Urbana-Champaign, IL, USA, 2006.

2. Li, X.; Parrott, L. An improved Genetic Algorithm for spatial optimization of multi-objective and multi-site land use allocation. Comput. Environ. Urban Syst. 2016, 59, 184-194. [CrossRef]

3. Yang, L.; Sun, X.; Peng, L.; Shao, J.; Chi, T. An improved artificial bee colony algorithmfor optimal land-use allocation. Int. J. Geogr. Inf. Sci. 2015, 29, 1-20. [CrossRef]

4. Malczewski, J.; Rinner, C. Multicriteria Decision Analysis in Geographic Information Science; Springer: Heidelberg, Germany, 2015.

5. Geertman, S.; Stillwell, J. Planning Support Systems in Practice; Springer: Heidelberg, Germany, 2012.

6. Malczewski, J. GIS and Multicriteria Decision Analysis; John Wiley \& Sons: New York, NY, USA, 1999.

7. Wang, H.; Shen, Q.; Tang, B.-S. A Review of Planning Support Systems for Urban Land Use Planning. In Proceedings of the 17th International Symposium on Advancement of Construction Management and Real Estate; Springer: Heidelberg, Germany, 2014.

8. Jankowski, P.; Fraley, G.; Pebesma, E. An exploratory approach to spatial decision support. Comput. Environ. Urban Syst. 2014, 45, 101-113. [CrossRef]

9. Vahidnia, M.H.; Alesheikh, A.A.; Alimohammadi, A. Hospital site selection using fuzzy AHP and its derivatives. J. Environ. Manag. 2009, 90, 3048-3056. [CrossRef] [PubMed]

10. Aydin, N.Y.; Kentel, E.; Duzgun, H.S. GIS-based site selection methodology for hybrid renewable energy systems: A case study from western Turkey. Energy Convers. Manag. 2013, 70, 90-106. [CrossRef]

11. Jelokhani-Niaraki, M.; Malczewski, J. A group multicriteria spatial decision support system for parking site selection problem: A case study. Land Use Policy 2015, 42, 492-508. [CrossRef]

12. Gorsevski, P.V.; Donevska, K.R.; Mitrovski, C.D.; Frizado, J.P. Integrating multi-criteria evaluation techniques with geographic information systems for landfill site selection: A case study using ordered weighted average. Waste Manag. 2012, 32, 287-296. [CrossRef] [PubMed]

13. Joerin, F.; Thériault, M.; Musy, A. Using GIS and outranking multicriteria analysis for land-use suitability assessment. Int. J. Geogr. Inf. Sci. 2001, 15, 153-174. [CrossRef]

14. Ullah, K.M.; Mansourian, A. Evaluation of Land Suitability for Urban Land-Use Planning: Case Study Dhaka City. Trans. GIS 2015, 20, 20-37. [CrossRef]

15. Arabsheibani, R.; Kanani Sadat, Y.; Abedini, A. Land suitability assessment for locating industrial parks: A hybrid multi criteria decision-making approach using Geographical Information System. Geogr. Res. 2016, 54, 446-460. [CrossRef]

16. Chuvieco, E. Integration of linear programming and GIS for land-use modelling. Int. J. Geogr. Inf. Sci. 1993, 7, 71-83. [CrossRef]

17. Moah, H.; Kanaroglou, P. A tool for evaluating urban sustainability via integrated transportation and land use simulation models. Urban Environ. 2009, 3, 28-46. [CrossRef]

18. Aerts, J.C.; van Herwijnen, M.; Stewart, T.J. Using simulated annealing and spatial goal programming for solving a multi site land use allocation problem. In International Conference on Evolutionary Multi-Criterion Optimization; Springer: Heidelberg, Germany, 2003.

19. Balling, R.J.; Taber, J.T.; Brown, M.R.; Day, K. Multiobjective urban planning using genetic algorithm. J. Urban Plan. Dev. 1999, 125, 86-99. [CrossRef]

20. Gong, J.; Liu, Y.; Chen, W. Optimal land use allocation of urban fringe in Guangzhou. J. Geogr. Sci. 2012, 22, 179-191. [CrossRef]

21. Masoomi, Z.; Mesgari, M.S.; Hamrah, M. Allocation of urban land uses by Multi-Objective Particle Swarm Optimization algorithm. Int. J. Geogr. Inf. Sci. 2013, 27, 542-566. [CrossRef]

22. Cao, K.; Batty, M.; Huang, B.; Liu, Y.; Yu, L.; Chen, J. Spatial multi-objective land use optimization: Extensions to the non-dominated sorting genetic algorithm-II. Int. J. Geogr. Inf. Sci. 2011, 25, 1949-1969. [CrossRef]

23. Stewart, T.J.; Janssen, R.; van Herwijnen, M. A genetic algorithm approach to multiobjective land use planning. Comput. Oper. Res. 2004, 31, 2293-2313. [CrossRef]

24. Masoumi, Z.; Maleki, J.; Mesgari, M.S.; Mansourian, A. Using an Evolutionary Algorithm in Multiobjective Geographic Analysis for Land Use Allocation and Decision Supporting. Geogr. Anal. 2017, 49, 58-83. [CrossRef] 
25. Abolhasani, S.; Taleai, M.; Karimi, M.; Rezaee Node, A. Simulating urban growth under planning policies through parcel-based cellular automata (ParCA) model. Int. J. Geogr. Inf. Sci. 2016, 30, 1-26. [CrossRef]

26. Ghavami, S.M.; Taleai, M.; Arentze, T. An intelligent spatial land use planning support system using socially rational agents. Int. J. Geogr. Inf. Sci. 2017, 31, 1022-1041. [CrossRef]

27. Zhang, H.; Zeng, Y.; Bian, L.; Yu, X. Modelling urban expansion using a multi agent-based model in the city of Changsha. J. Geogr. Sci. 2010, 20, 540-556. [CrossRef]

28. Jelokhani-Niaraki, M.; Malczewski, J. The decision task complexity and information acquisition strategies in GIS-MCDA. Int. J. Geogr. Inf. Sci. 2015, 29, 327-344. [CrossRef]

29. Chen, J. GIS-based multi-criteria analysis for land use suitability assessment in City of Regina. Environ. Syst. Res. 2014, 3, 13. [CrossRef]

30. Dubois, D.; Prade, H. Operations on fuzzy numbers. Int. J. Syst. Sci. 1978, 9, 613-626. [CrossRef]

31. Hanss, M. Applied Fuzzy Arithmetic; Springer: Heidelberg, Germany, 2005.

32. Kaufman, A.; Gupta, M.M. Introduction to Fuzzy Arithmetic: theory and applications; Van Nostrand Reinhold Company: New York, NY, USA, 1991.

33. Ray, K.S. Soft Computing and Its Applications, Volume One: A Unified Engineering Concept; CRC Press: Oakville, ON, Canada, 2014; Volume 1.

34. Chen, C.-T. Extensions of the TOPSIS for group decision-making under fuzzy environment. Fuzzy Sets Syst. 2000, 114, 1-9. [CrossRef]

35. Ma, M.; Kandel, A.; Friedman, M. A new approach for defuzzification. Fuzzy Sets Syst. 2000, 111, $351-356$. [CrossRef]

36. Zadeh, L.A. The concept of a linguistic variable and its application to approximate reasoning-I. Inf. Sci. 1975, 8, 199-249. [CrossRef]

37. Coutinho-Rodrigues, J.; Sousa, N.; Natividade-Jesus, E. Design of evacuation plans for densely urbanised city centres. Proc. Inst. Civil Engineers 2016, 169, 160-172. [CrossRef]

38. Cao, K.; Huang, B.; Wang, S.; Lin, H. Sustainable land use optimization using Boundary-based Fast Genetic Algorithm. Comput. Environ. Urban Syst. 2012, 36, 257-269. [CrossRef]

39. ReVelle, C.S.; Eiselt, H.A. Location analysis: A synthesis and survey. Eur. J. Oper. Res. 2005, 165, 1-19. [CrossRef]

40. Masoomi, Z. Modeling the physical effects of urban land-uses change using optimization algorithms and spatial analysis. In Geodesy and Geomatics Engineering, Geospatial Information Systems (GIS); Khajeh Nasir Toosi University of Technology: Tehran, Iran, 2013. (In Persian)

41. Taleai, M.; Sharifi, A.; Sliuzas, R.; Mesgari, M. Evaluating the compatibility of multi-functional and intensive urban land uses. Int. J. Appl. Earth Observ. Geoinf. 2007, 9, 375-391. [CrossRef]

42. Tang, Q.; Li, Y.; Xu, Y. Land suitability assessment for post-earthquake reconstruction: A case study of Lushan in Sichuan, China. J. Geogr. Sci. 2015, 25, 865-878. [CrossRef]

43. Maab-Consulting-Engineers. Definitions and Concepts of Urban Land-Uses and Determining the Per Capita; Iran's Supreme Council for Planning and Architecture: Tehran, Iran, 2010. (In Persian)

44. Chou, S.-Y.; Chang, Y.-H.; Shen, C.-Y. A fuzzy simple additive weighting system under group decision-making for facility location selection with objective/subjective attributes. Eur. J. Oper. Res. 2008, 189, 132-145. [CrossRef]

45. Haque, A.; Asami, Y. Optimizing urban land use allocation for planners and real estate developers. Comput. Environ. Urban Syst. 2014, 46, 57-69. [CrossRef]

46. Porta, J.; Parapar, J.; Doallo, R.; Rivera, F.F.; Santé, I.; Crecente, R. High performance genetic algorithm for land use planning. Comput. Environ. Urban Syst. 2013, 37, 45-58. [CrossRef]

47. Habibi, M.; Masaeli, S. Land per Capita Standard for Urban Land Uses; National Land and Housing Organization: Tehran, Iran, 1999. (In Persian)

48. Farnahad, C.E. Development Pattern of District 7 of Tehran; Tehran Municipality: Tehran, Iran, 2005. (In Persian)

49. Deb, K. An efficient constraint handling method for genetic algorithms. Comput. Methods Appl. Mech. Eng. 2000, 186, 311-338. [CrossRef] 